\title{
Simulation of Motorcycle Smart Handling With Addition Gyroscopic Component
}

\author{
I Ketut Adi Atmika ${ }^{1}$, I D G Ary Subagia ${ }^{1}$, I Nyoman Sutantra ${ }^{2}$, dan Agus Sigit Pramono ${ }^{2}$
}

\begin{abstract}
Motorcycle in its operation needs high stability. To improve a stability of motorcycle especially in turning direction is done by many methods. The handling turn inclination angle of motorcycle with addition gyroscopic component will be discussed in this research. Gyroscopic is systems which have function to against from Centrifugal (Fc) force. The aim of using Gyroscopic is to control and handling turn inclination angle to avoid skidding.This research uses of simulation model with input of design and dynamic parameter. Speed variable to be used are 40, 50, $60,70,80,90,100 \mathrm{~km} / \mathrm{hour}$. The simulation is processed by Matlab 7.0.1. The result of research is concluded as : the Gyroscopic has controlled skid performance and inclination angle of motorcycle about $11 \%$.
\end{abstract}

Keywords - Handling, Turning Direction, Centrifugal Force, Gyroscopic, Motorcycle

\section{Pendahuluan}

$\mathrm{K}$ endaraan bermotor khususnya sepeda motor adalah jenis kendaraan yang digerakkan dengan sistem dua roda. Sepeda motor dalam operasinya membutuhkan kualitas kesetabilan yang sangat tinggi mengingat sepeda motor membutuhkan keseimbangan pada setiap manuvernya.

Gerak belok adalah fenomena yang paling kritis dari setiap kendaraan, terlebih pada sepeda motor. Gerak belok pada sepeda motor sangat mungkin terjadinya kehilangan keseimbangan tergantung pada besarnya sudut kemiringan belok, radius belok, efek gaya centrifugal yang bekerja pada pusat massa kendaraan dan juga faktor kecepatan. Fenomena saat sepeda motor belok dimana jika tidak ada pengendalian sudut kemiringan yang baik dapat mengakibatkan kendaraan tersebut loss control.

Untuk dapat mengendalikan sudut kemiringan belok sepeda motor agar tidak loss control dimungkinkan menggunakan Gyroscopic. Pengendalian dengan Gyroscopic adalah suatu system yang berfungsi untuk melawan gaya centrifugal yang terjadi, dimana dengan Gyroscopic ini akan didapatkan sudut kemiringan yang ideal sehingga kendaraan tidak loss control.

Naskah diterima pada tanggal 1 Mei 2009, selesai revisi pada 5 Mei 2009

${ }^{1}$ I K. Adi Atmika dan I D G Ary Subagia adalah dosen Jurusan Teknik Mesin, Fakultas Teknik, Universitas Udayana, Bali, INDONESIA

e-mail : tutadi2001@yahoo.com; tutadi@me.unud.ac.id

2 I N. Sutantra dan Agus S. Pramono adalah dosen Jurusan Teknik Mesin, FTI, Institut Teknologi Sepuluh Nopember, Surabaya, INDONESIA
Pada akhirnya dengan bantuan simulasi pada program Matlab 7.0.1 diharapkan dapat memberikan gambaran yang jelas tentang pengendalian stabilitas gerak belok sepeda motor melalui pengontrolan Gyroscopic.

Adi Atmika [1] menjelaskan tentang kontrol torsi dengan CVT untuk memperbaiki stabilitas arah kendaraan. Paper ini menjelaskan analisa stabilitas dari kontrol torsi roda penggerak dengan mengatur ratio transmisi menggunakan sistem CVT. Model kendaraan dibuat secara lengkap dengan input kondisi dan parameter operasi dimana sistem itu bekerja, kemudian disimulasikan dengan mengambil setting point ratio slip pada koefisien gesek yang optimum. Analisa stabilitas difokuskan pada perilaku gerakan belok kendaraan. Yawrate respon dibandingkan dengan yawrate ackermannya, untuk mendapatkan gambaran kinerja perilaku arah kendaraan. Kinerja perilaku kendaraan cukup baik dimana yawrate respons sangat cepat mencapai kondisi steady untuk mendekati yawrate ackermannya.

Ary Subagia [2] dalam papernya yang berjudul "Desain dan Simulasi Dinamik sudut Belok Roda Belakang (Four Wheel Steering Sistem) dengan Pengendalian Traksi Kendaraan", mengulas sistem kemudi 4 roda untuk mendapatkan kinerja kestabilan kendaraan yang lebih baik.

Ary Subagia, Adi Atmika, Komala Dewi [2] menjelaskan tentang analisa karateristik traksi pada sepeda motor (110 cc, 4 tak) dengan kontinyu variabel transmision. Karakteristik traksi yang dihasilkan oleh roda penggerak ditinjau dari ratio transmisi dan tingkat transmisi. Analisa karateristik traksi roda penggerak dilakukan dengan menggunakan metode quasi dinamik dengan kendaraan model adalah motor Mio $110 \mathrm{cc}, 4$ tak. Perhitungan didasarkan pada input parameter kendaraan meliputi kecepatan, daya motor, dan perilaku dinamik kendaraan model. Kemudian karateristik traksi CVT terhadap traksi yang dihasilkan dianalisa mempergunakan kontrol traksi melalui simulasi mode, dengan kondisi jalan lurus.

Tatsuhiko Abe,dkk melakukan penelitian tentang konsep terbaru sistem kontrol traksi, yaitu dengan HTCS (Hybrid Traction Control System) yang menawarkan kinerja dalam hal memperbaiki TCS dengan EIB (Engine Inertia Brake).

I Nyoman Sutantra, Agus Sigit P, Yunarko Triwinarno, M. Harly dalam papernya "Improvement of ABS Performance Trough Application of Yaw Control Index" [3], bahwa gerakan yawing adalah salah satu parameter kunci dalam menentukan stabilitas arah kendaraan

Studi tentang perilaku dinamik gerak belok sepeda motor dengan pengendalian Gyroscopic. Bagaimana pe- 
rilaku sepeda motor dengan Gyroscopic terhadap pengaruh kecepatan saat bergerak belok. Untuk menjawab pengaruh tersebut diatas, dilakukan dengan mempergunakan metode simulasi.

\section{METODOLOGI}

Pemodelan. Model kendaraan terdapat pada Gambar

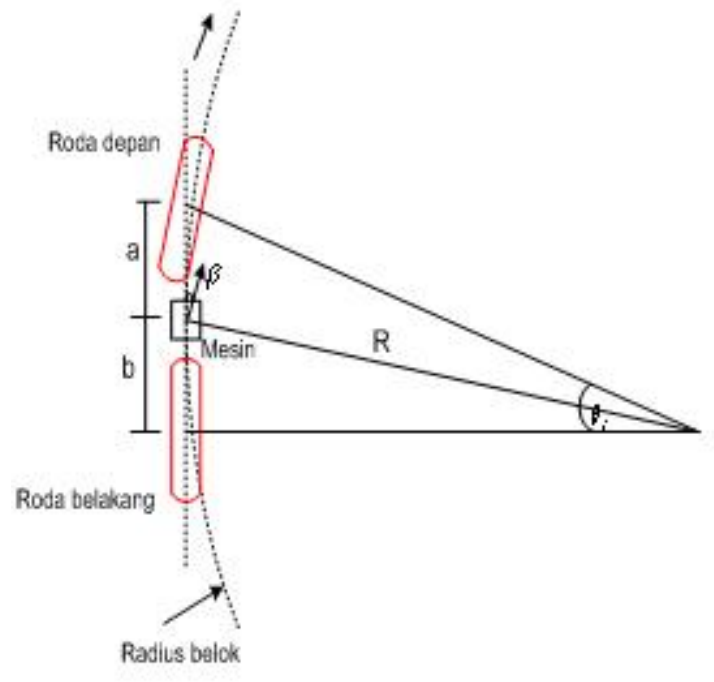

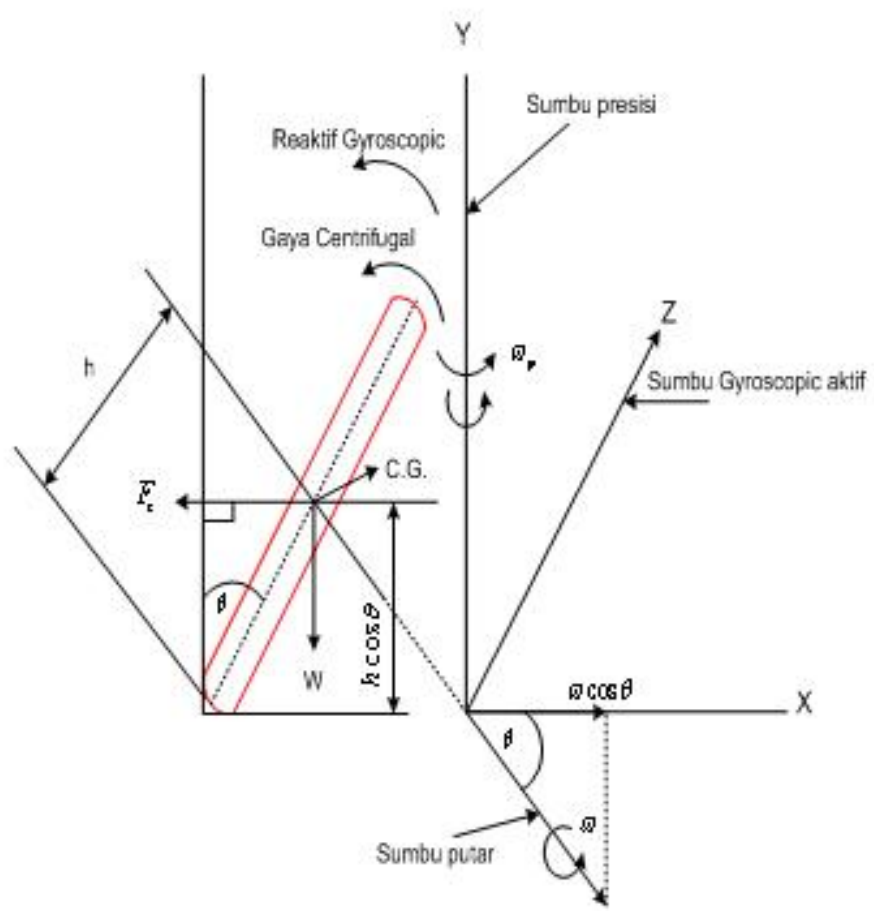

Gambar 1. Model Kendaraan
Keterangan :

$\mathrm{M}$

$\mathrm{W}$

$\mathrm{H}$

$\mathrm{r}_{\mathrm{W}} \quad=$ jari - jari roda

$\mathrm{R} \quad=$ jari - jari lintasan belok

$\mathrm{I}_{\mathrm{w}} \quad=$ masa momen inertia kedua roda

$\mathrm{I}_{\mathrm{E}} \quad=$ masa memen inertia dari bagian yang berputar dari mesin

$\omega_{W} \quad=$ percepatan sudut dari roda

$\omega_{E} \quad=$ percepatan sudut dari mesin

$\mathrm{G}=$ rasio roda gigi pada transmisi $\left(\omega_{E} / \omega_{W}\right)$

$\mathrm{v} \quad=$ kecepatan linear dari kendaraan

$\theta \quad=$ sudut kemiringan belok

Matematis Model. Berkaitan dengan tahapan dalam pembuatan simulasi, perhitungan dan analisa data berdasarkan persamaan matematik sebagai berikut :

Gaya Sentrifugal. Gaya Sentrifugal yang terjadi pada kendaraan dirumuskan sebagai berikut:

$\mathrm{F}_{\mathrm{c}}=\frac{W}{g} \frac{V^{2}}{R}$

Radius Belok Nyata. Radius Belok dirumuskan dengan persamaan

$R_{i}=\frac{a+b}{\delta_{f}} 57,29$
Gaya Normal. Dengan mengabaikan beban angin gaya normal yang terjadi pada roda depan dan belakang dirumuskan sebagai berikut :

$F_{z f}=\frac{b}{a+b}\left[W \cos \theta+F_{c} \cos \beta \cdot \sin \theta\right]+\frac{h \cdot F_{c} \sin \beta}{a+b}$

$F_{z r}=\frac{a}{a+b}\left[W \cos \theta+F_{c} \cos \beta \cdot \sin \theta\right]+\frac{h \cdot F_{c} \sin \beta}{a+b}$

Analisa Skid. Analisa Skid Menggunakan persamaan $F_{c f}=\mu \cdot F_{z f}$ dan $F_{c r}=\mu \cdot F_{z r}$

Kecepatan Maksimum Sebelum Skid. Kecepatan maksimum sebelum skid pada roda depan dan belakang menggunakan persamaan :

$V_{f s}=\sqrt{\frac{\left(\mu \cdot F_{z f}\right) \cdot\left(\frac{a+b}{b}\right)+W \sin \theta}{\cos \beta \cdot \cos \theta} \cdot \frac{g \cdot R}{w}}$

$V_{r s}=\sqrt{\frac{\left(\mu \cdot F_{2 f}\right) \cdot\left(\frac{a+b}{a}\right)+W \sin \theta}{\cos \beta \cdot \cos \theta} \cdot \frac{g \cdot R}{w}}$

Theta Maksimum Sebelum Skid. Theta Maksimum sebelum skid dirumuskan dengan

$\tan \theta=\frac{v^{2}-R \cdot g \cdot \mu}{R \cdot g+\mu \cdot v^{2}}$

Efek Gyroscopic. Kopel Gyroscopic yang bekerja untuk mengendalikan sudut kemiringan belok dirumuskan dengan persamaan

$C=\frac{v^{2}}{R \cdot r_{W}}\left(2 I_{W}+G I_{E}\right) \cos \theta$

Kesetabilan Gaya. Kesetabilan gaya yang pada akhirnya akan membentuk sudut kemiringan yang terkendali dirumuskan dengan

Gaya Sentrifugal + Gyroscopic couple $=m \cdot g \cdot h \cdot \sin \theta$ 


\section{Pemodelan simulasi}

\section{Simulink diagram}

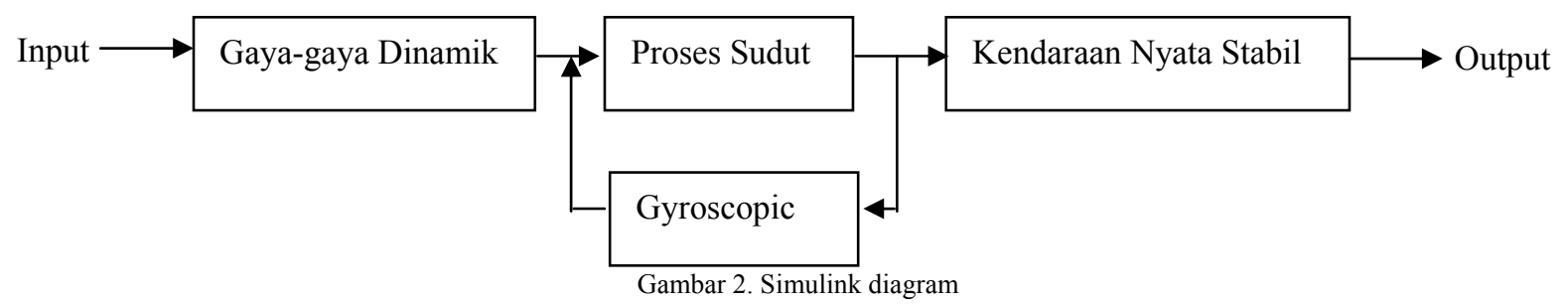

\section{Diagram alir Simulasi}

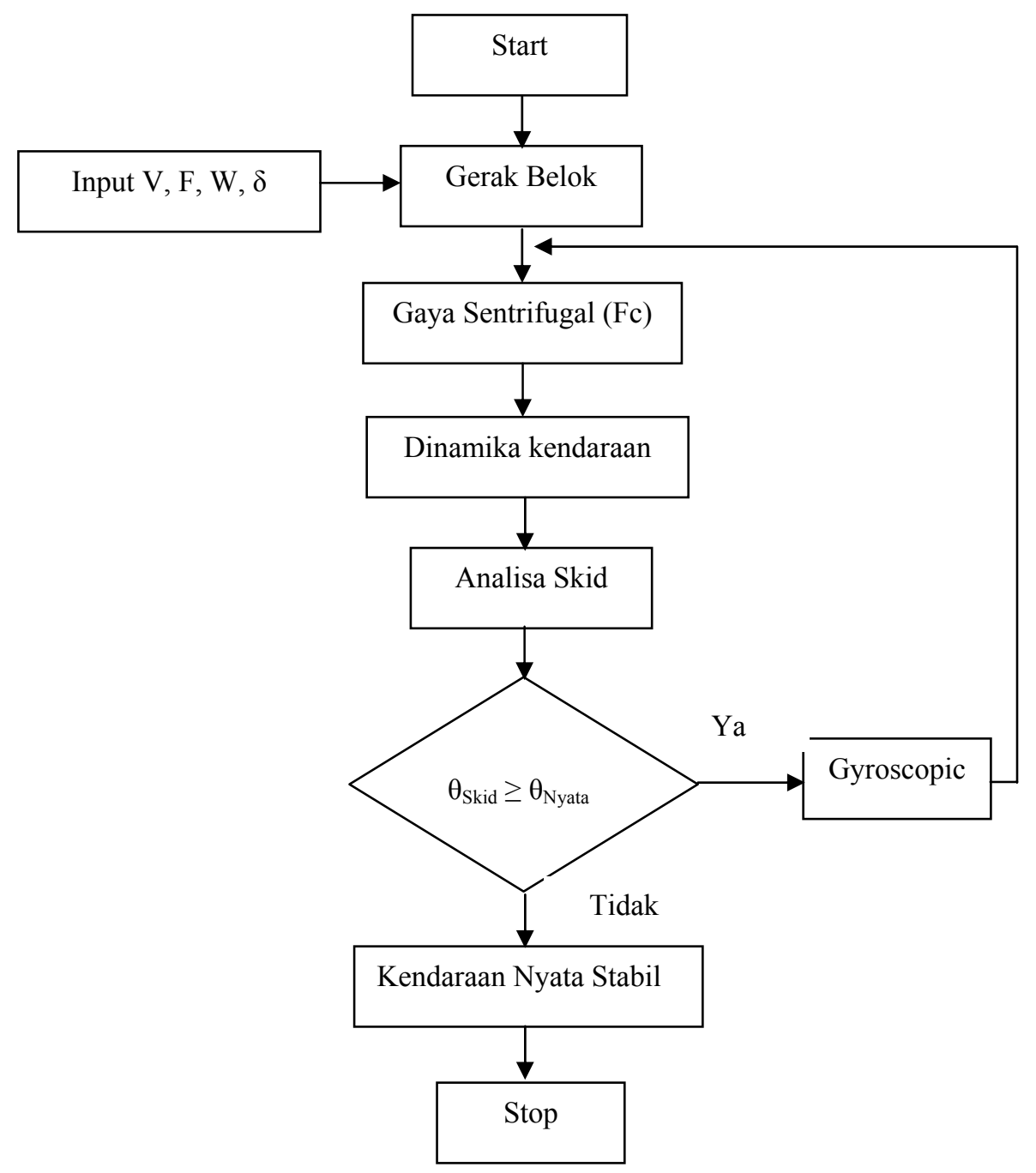

Gambar 3. Diagram alir simulasi

Secara umum tahapan dan proses penyusunan model simulasi dilaksanakan dengan langkah-langkah sebagai berikut : Memilih parameter simulasi yang terdiri atas variable konstan maupun variable terhitung dalam rumusan yang berpengaruh pada gerak belok dimana $\mathrm{Va}-$ riabel konstan yang digunakan adalah Sudut steer $(\delta)$, Radius belok (R), Berat kendaraan (W), Gaya - gaya dinamik kendaraan, dan Koefisien gesek ban dan jalan $(\mu)$. Variabel yang yang dipergunakan adalah faktor kecepatan kendaraan saat bergerak belok dimana divariasikan dari 40, 50, 60, 70, 80, 90, $100 \mathrm{~km} / \mathrm{jam}$. Mengha- silkan Gaya Sentrifugal yang terhitung dari rumusan. Terjadi dinamika kendaran. Dari dinamika kendaraan kemudian dilakukan analisa skid, melalui analisa skid diperoleh sudut kemiringan belok skid (theta skid). Suatu kendaraan dikatakan memiliki kualitas kesetabilan yang lebih baik jika sudut kemiringan belok nyata (theta nyata) dapat diberikan melebihi sudut kemiringan belok skid tetapi kendaraan tetap dalam keadaan stabil. Jika theta skid lebih besar dari theta nyata kontrol Gyroscopic mulai bekerja, jika theta skid lebih kecil dari theta nyata proses selesai. 


\section{Blok diagram simulasi}

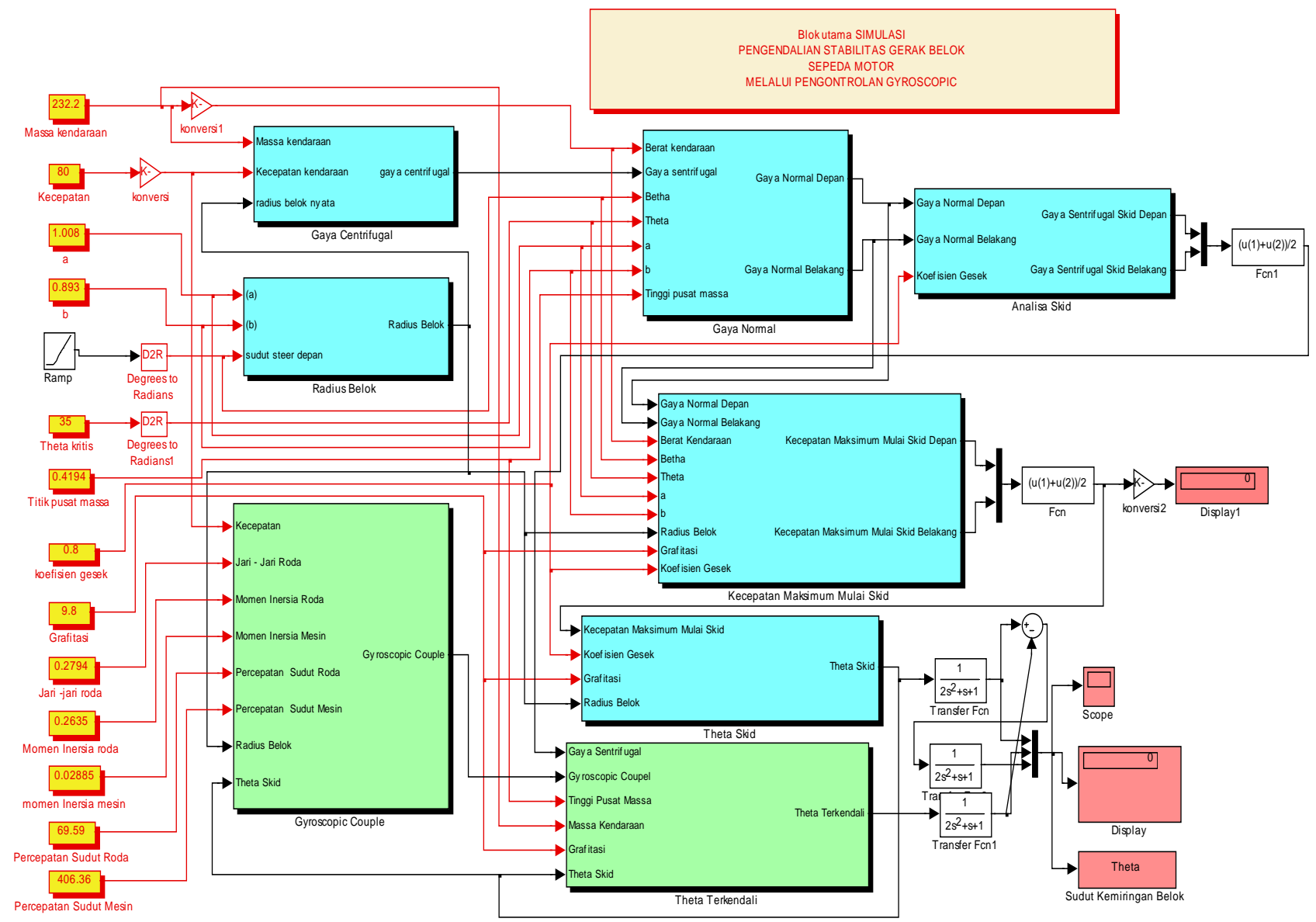

\section{HASIL DAN PEMBAHASAN}

\section{Hasil Simulasi}

Dari simulasi yang telah dibuat didapatkan grafik sudut kemiringan belok (theta) terhadap waktu dengan variasi kecepatan dari 40, 50, 60, 70, 80, 90, $100 \mathrm{~km} / \mathrm{jam}$, seperti ditunjukkan pada Gambar 4 sampai dengan gambar 10.

Dari grafik pada Gambar 4 dapat dilihat bahwa pada kecepatan $40 \mathrm{~km} / \mathrm{jam}$ pada kisaran waktu 0 -30 milisecond terjadi fluktuasi dari sudut kemiringan belok, dalam artian terjadi perubahan keadaan baik peningkatan maupun penurunan untuk menjadi konstan, pada kisaran waktu 50 milisecond keadaan kostan mulai tercipta dan didapatkan theta skid sebesar $18,78^{\circ}$ dan theta terkendali sebesar $19,78^{\circ}$. Kemudian secara lengkap di-

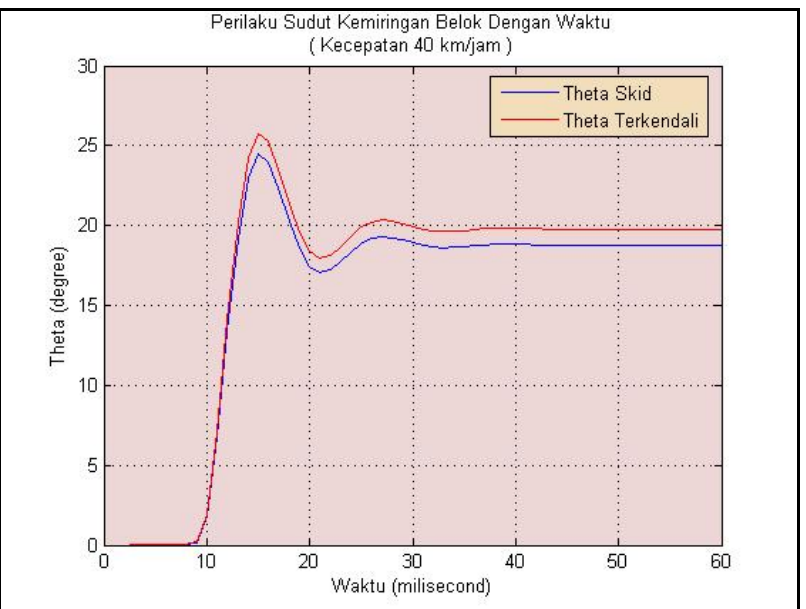
tunjukkan pada Tabel 1.

Gambar 4. Hubungan theta terhadap waktu pada kecepatan $40 \mathrm{~km} / \mathrm{jam}$ 


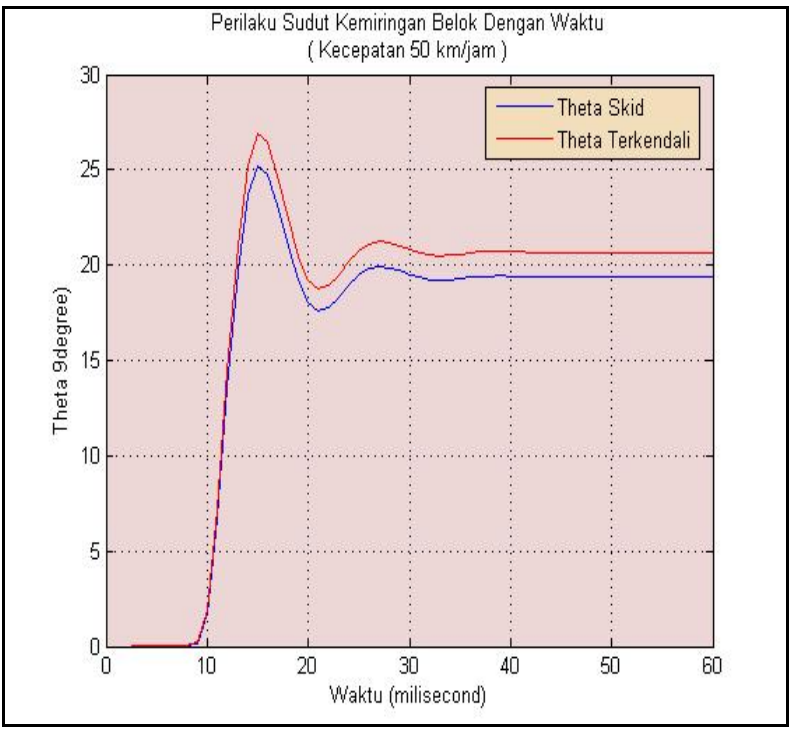

Gambar 5. Hubungan theta terhadap waktu pada kecepatan 50 km/jam

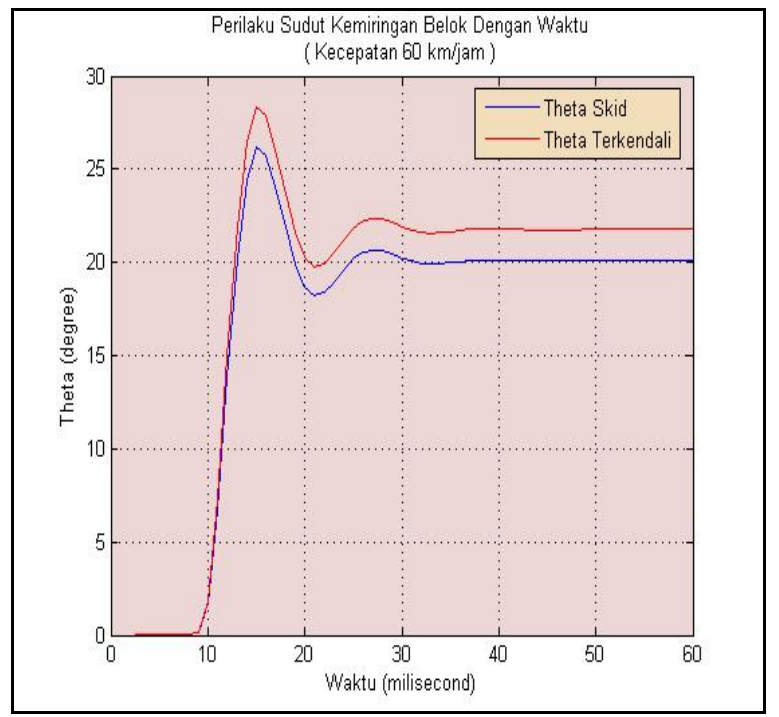

Gambar 6. Hubungan theta terhadap waktu pada kecepatan 60 km/jam

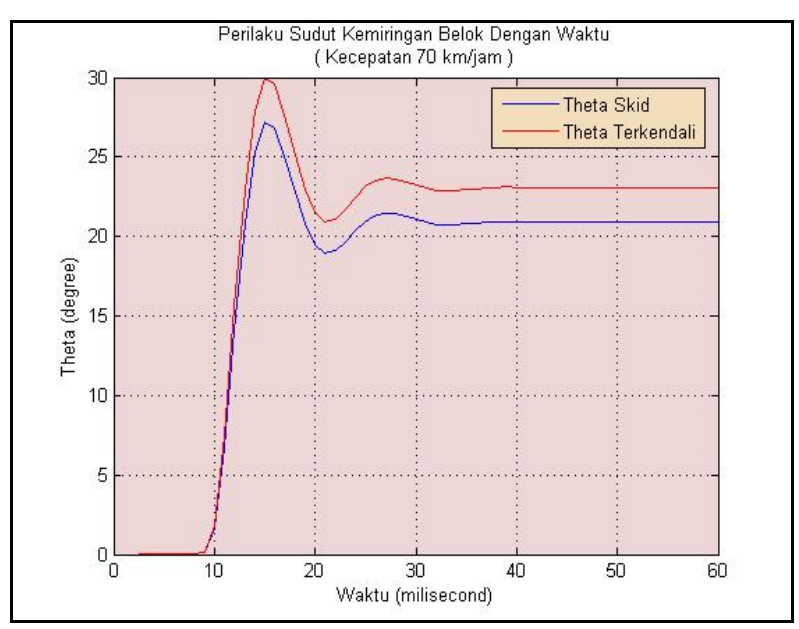

Gambar 7. Hubungan theta terhadap waktu pada kecepatan 70 km/jam

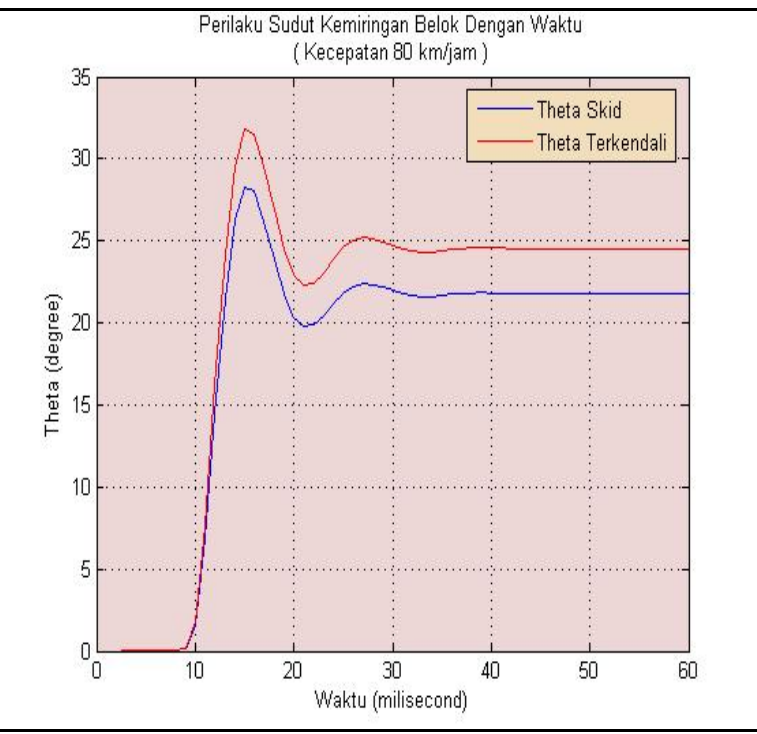

Gambar 8. Hubungan theta terhadap waktu pada kecepatan 80 km/jam

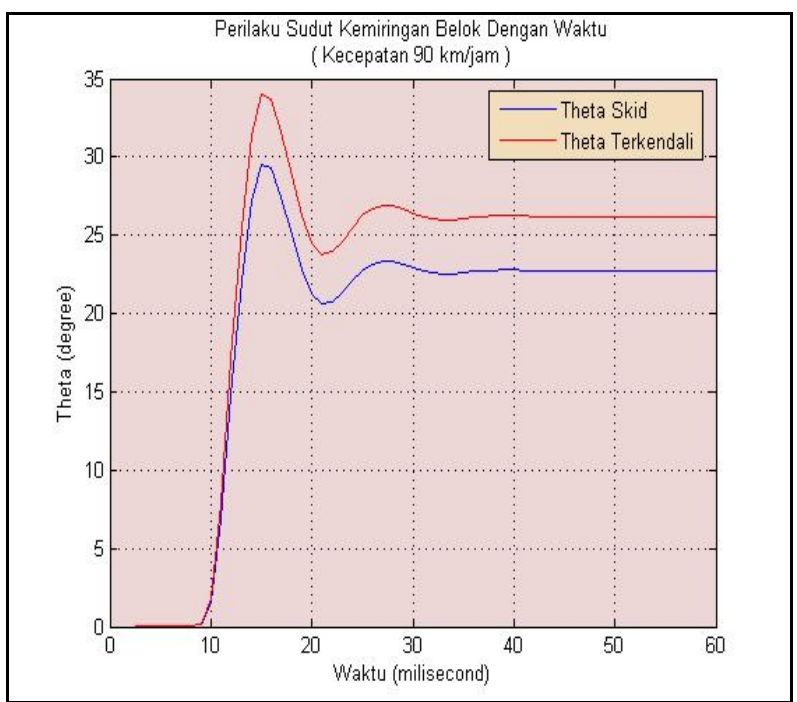

Gambar 9. Hubungan theta terhadap waktu pada kecepatan 90 km/jam

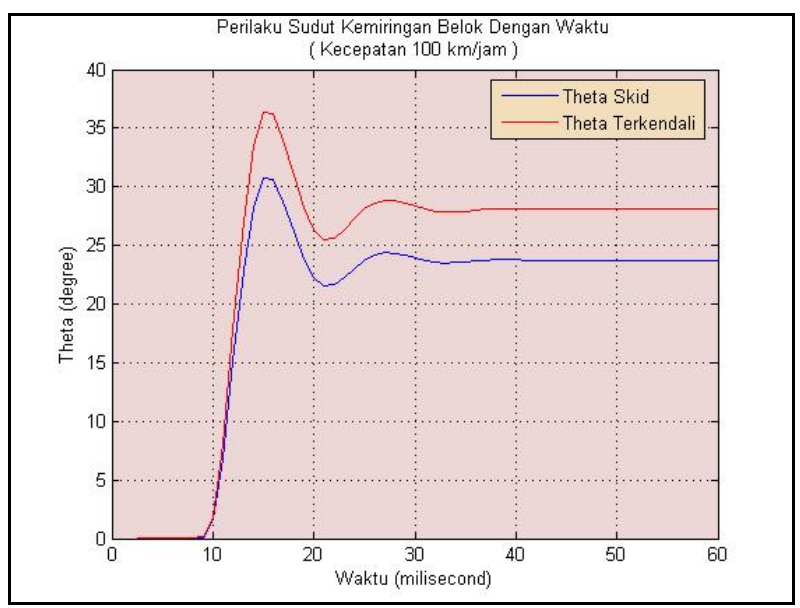

Gambar 10. Hubungan theta terhadap waktu pada kecepatan 100 $\mathrm{km} / \mathrm{jam}$ 
Dari grafik pada gambar 4 dapat dilihat bahwa pada kecepatan $40 \mathrm{~km} / \mathrm{jam}$ pada kisaran waktu 0 -30 milisecond terjadi fluktuasi dari sudut kemiringan belok, dalam artian terjadi perubahan keadaan baik peningkatan maupun penurunan untuk menjadi konstan, pada kisaran waktu 50 milisecond keadaan kostan mulai tercipta dan didapatkan theta skid sebesar $18,78^{\circ}$ dan theta terkendali sebesar $19,78^{\circ}$. Kemudian secara lengkap ditunjukkan pada tabel 1 .

\section{Pembahasan}

Saat bergerak belok akan timbul gaya sentrifugal $(F C)$ yang arahnya keluar dari bidang belok, untuk menstabilkan gaya sentifugal yang terjadi dan agar kendaraan (sepeda motor) tetap stabil maka sepeda motor perlu dimiringkan sehingga membentuk suatu sudut, sudut kemiringan belok ini disebut dengan theta yang dinotasikan dengan $(\theta)$.

Saat bergerak belok dalam setiap tingkatan kecepatan terdapat sudut kemiringan belok maksimal (theta maksimal). Karena tidak adanya batasan yang jelas terhadap sudut kemiringan belok maksimal maka pengendaran sering melakukan kesalahan dengan memberikan sudut kemiringan yang berlebih saat bergerak belok yang menyebabkan kendaraan tersebut mengalami loss control seperti skid atau terguling.

Penambahan komponen Gyroscopic merupakan suatu langkah untuk meningkatkan kestabilan kendaraan saat bergerak belok, dengan penambahan komponen Gyroscopic terdapat perlawanan terhadap gaya sentrifugal yang terjadi, dengan menggunakan prinsip keseimbangan gaya, penambahan komponen Gyroscopic ini akan menghasilkan theta terkendali dimana theta terkendali merupakan sudut kemiringan ideal dan yang aman bagi pengendara saat bergerak belok.

Berdasarkan Tabel 1 dapat dinyatakan dalam bentuk grafik hubungan theta terkendali dengan kecepatan seperti ditunjukkan pada Gambar 11.

Dari Tabel 1 dan Gambar 4 dapat dilihat bahwa meningkatnya kecepatan dalam bergerak belok membutuhkan theta terkendali yang semakin besar untuk menyetabilkan kendaraan.

Untuk mengetahui besarnya kemampuan gyroscopic dalam mengontrol kesetabilan dalam bergerak belok ditampilkan theta skid kendaraan ditunjukkan pada Tabel 2 .

Berdasarkan Tabel 2, hubungan theta skid dengan kecepatan ditunjukkan pada Gambar 12. Dari Tabel 2 Gambar 5 dapat dilihat bahwa meningkatnya kecepatan dalam bergerak belok menyebabkan theta skid yang semakin besar. jika memiringkan kendaraan sebesar theta skid saat bergerak belok maka kendaraan akan loss control. Dengan menambahkan komponen Gyroscopic saat theta skid terjadi maka kompoenen Gyroscopic akan mengontrol gaya setrifugal, sehingga terjadi kestabilan gaya dan kondisi loss control dapat dihindari. Hubungan antara theta skid dengan theta terkendali seperti pada Gambar 13.

Gambaran peningkatan sudut kemiringan kendaraan saat bergerak belok dengan penambahan komponen $G y-$ roscopic, besarnya peningkatan sudut kemiringan belok ditunjukkan pada Tabel 3. Secara rata-rata peningkatan sudut kemiringan belok dengan penambahan komponen Gyroscopic sebesar $11 \%$.

TABEL 1

THETA TERKENDALI

\begin{tabular}{cc}
\hline Kecepatan & Theta Terkendali \\
\hline$(\mathrm{Km} / \mathrm{jam})$ & $($ Degree $)$ \\
\hline 40 & 19,78 \\
50 & 20,68 \\
60 & 21,76 \\
70 & 23,05 \\
80 & 24,53 \\
90 & 26,2 \\
100 & 28,08 \\
\hline
\end{tabular}

TABEL 2

\begin{tabular}{cc}
\multicolumn{2}{c}{ THETA SKID } \\
\hline Kecepatan & Theta Skid \\
\hline$(\mathrm{Km} / \mathrm{jam})$ & ( Degree) \\
\hline 40 & 18,78 \\
50 & 19,38 \\
60 & 20,09 \\
70 & 20,9 \\
90 & 21,78 \\
100 & 22,72 \\
\hline
\end{tabular}

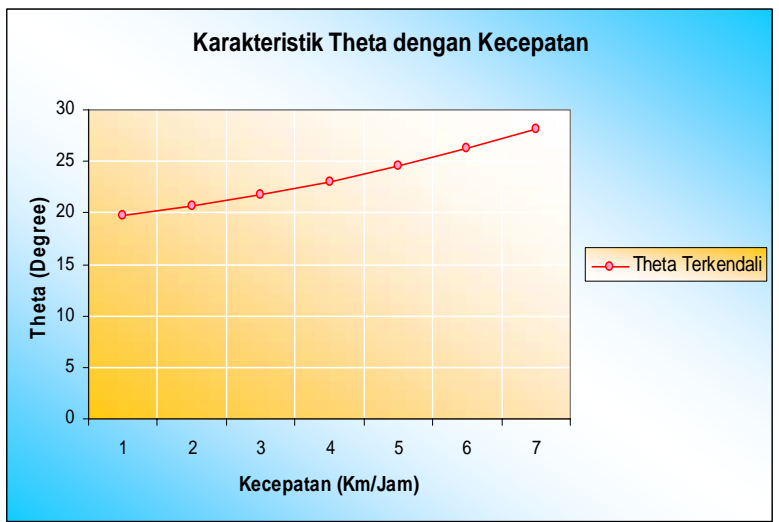

Gambar 11. Hubungan theta terkendali dengan kecepatan

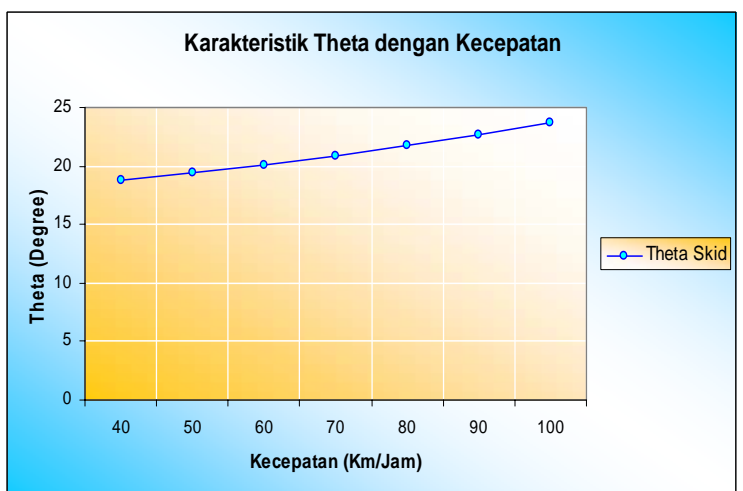

Gambar 12. Hubungan theta skid dengan kecepatan 
TABEL 3

PENINGKATAN SUDUT KEMIRINGAN BELOK DENGAN PENAMBAHAN KOMPONEN GYROSCOPIC

\begin{tabular}{ccccc}
\hline \multirow{2}{*}{ Kecepatan } & Theta & Theta & \multicolumn{2}{c}{ Peningkatan sudut } \\
\cline { 2 - 5 } & Skid & Terkendali & kemiringan Belok \\
\hline \multirow{2}{*}{$(\mathrm{Km} /$ jam $)$} & $($ Degree $)$ & ( Degree) & (Degree) & $\%$ \\
\hline 40 & 18,78 & 19,78 & 1 & 5,32 \\
50 & 19,38 & 20,68 & 1,3 & 6,71 \\
60 & 20,09 & 21,76 & 1,67 & 8,31 \\
70 & 20,9 & 23,05 & 2,15 & 10,29 \\
80 & 21,78 & 24,53 & 2,75 & 12,63 \\
90 & 22,72 & 26,2 & 3,48 & 15,32 \\
100 & 23,71 & 28,08 & 4,37 & 18,43 \\
\hline & Total & & $\mathbf{2 , 3 9}$ & $\mathbf{1 1 , 0 0}$ \\
\hline
\end{tabular}

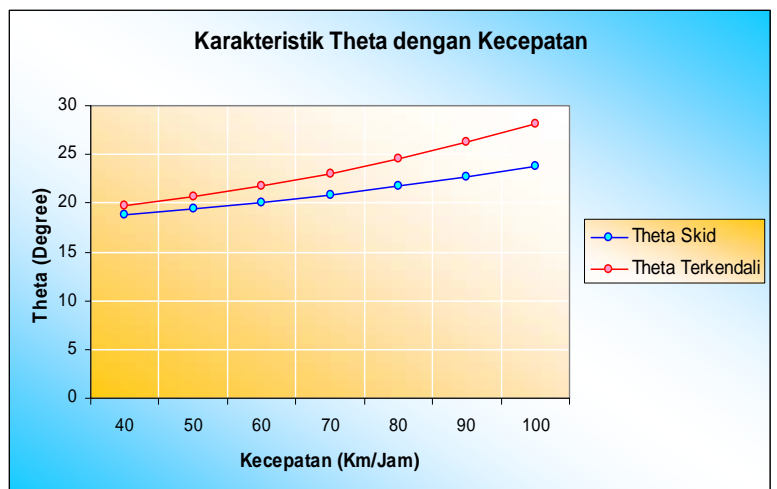

Gambar 13. Hubungan theta skid dan terkendali dengan kecepatan

\section{HASIL DAN PEMBAHASAN}

Dari hasil simulasi dan analisa yang dilakukan dapat disimpulkan bahwa penambahan komponen Gyroscopic theta skid dapat dikendalikan sehingga kondisi loss control dapat dihindari, dalam keadaan standar sepeda motor pada kecepatan $40-100 \mathrm{~km} / \mathrm{jam}$ kan mengalami skid pada sudut kemiringan $18,78^{\circ}-23,71^{\circ}$, penambahan komponen Gyroscopic pada kecepatan 40 - $100 \mathrm{~km} / \mathrm{jam}$ theta terkendali didapatkan sebesar $19,78^{\circ}-28,08^{\circ}$, dan penambahan komponen Gyroscopic dapat meningkatkan sudut kemiringan belok sebesar $11 \%$ dari kondisi tanpa menggunakan komponen Gyroscopic.

\section{DAFTAR PUSTAKA}

[1] Atmika, Adi. 2004. Simulasi Pengendalian Stabilitas Arah Kendaraan Melalui Pengontrolan Torsi dengan Continous Variable Transmission (CVT), Pasca sarjana ITS Surabaya.

[2] Subagia, Ary, Adi Atmika, Komala Dewi. 2005. Analisa Karateristik Traksi Pada Sepeda Motor (110 cc, 4 strokes) with Continous Variabel Transmission (CVT) System. Prosiding SNTTM IV, Bali.

[3] Sutantra, N.et al. 2002, "Improvement of ABS Performance Through Application of Yaw Control Index", $6^{\text {th }}$ Symposium on Advance Vehicle Control (AVEC) Japan 